\title{
NEUROLOGICAL LETTER FROM ...
}

With 16 million inhabitants the Dutch take some meagre consolation in being the biggest of the small European countries. That they no longer rule the world's oceans is a loss felt less deeply than by some of our neighbours. At any rate, the Dutch now dominate the holiday resorts in France and Spain.

\section{MEDICALSCHOOLS}

In the1980stherewereabout200studentsper year in each of theeight medical schools, at atimewhen the eternally false predictions about the required number of doctors had resulted in an oversupply. Theinevitableswing in theopposite direction began in thecurrent decade, hencethenumber of first-year students has now increased to almost 400 per university. The numerous applicants are selected by lottery, with only some weighting based on the results of the national finals in secondary school. Squandering young talent by the dice has always sounded strange to foreign ears. Yet the interview system is prone to bias: put two Dutch peopletogether and they arebound to have several acquaintances in common. In the last few years some medical schools have nonetheless experimented with selecting some of their entrants for themselves, but the process proved extremely labour-intensive and the 'super students' did not perform appreciably better than their pers.
Thecurriculum has been 'modernised' about every five years in most universities. Problembased learning in small groupsisnow derigueur but awareness is growing that clinical lectures should bereintroduced and that doctors require a modicum of anatomical knowledge.

\section{TRAINING PROGRAMMES IN NEUROLOGY}

Eight university hospitals and eight general hospitals have been certified as institutions for training in neurology. Thepolitics governing the allotment of training positions is characterized by a delicatebalance of power between thesetwo factions. Theodd result isthatonein threeDutch neurologistshasno academictraining. Theprocess itself consists of doing training (registrar, resident) jobsfor six years, including oneyear of clinical neurophysiology. M ost of thesestintsare at the mother institution. The programme includes rotationsin related disciplines: neurosurgery, paediatric neurology, psychiatry (optional) and intensive care medicine (optional). Specialist training in general medicine before entering neurology is not required. ThereforeD utch neurologistsaremostly uncomfortablewith reading ECGsand treating diabetes, but they arequickly catching up with the new trend of treating their vascular patients with statins and antihypertensiveagents as well as with antithrombotic drugs. 
Working hoursfor residents are limited by law to $48 \mathrm{~h}$ per week. The increasing number of women in theprofession has created ademand for part-time training (fewer hours, for more years), yet it is still rare and it can be accommodated only in large centres. Formal teaching sessions for residents are increasingly required. A single person is responsible for each local training programme. Its quality isformally reviewed by a committee of peers at least every five years.

In most university hospitals the training can be combined with some three years of re search, often in split periods. When enough external research grants are obtained such an arrangement may even become

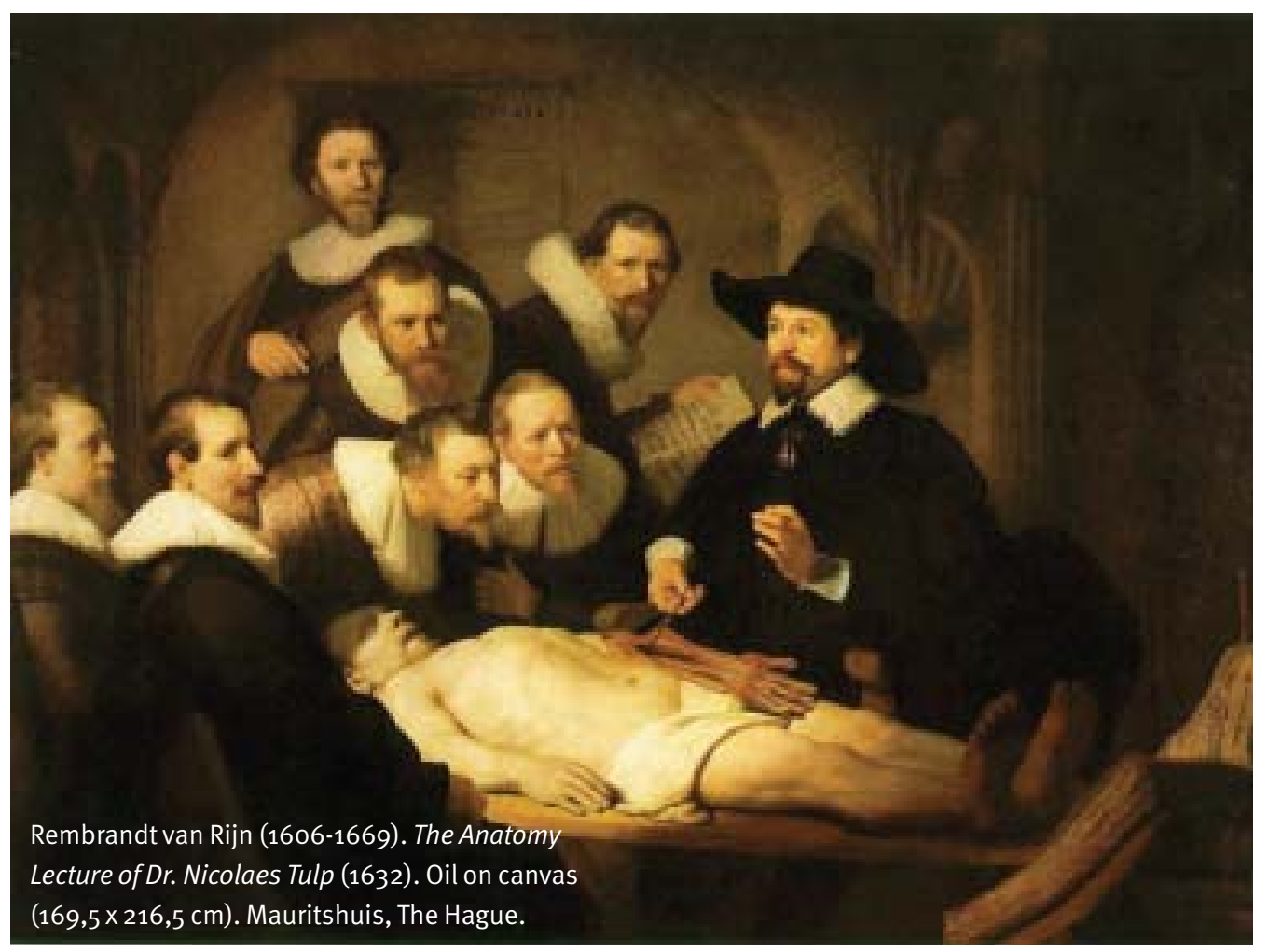
the rule. An extra bonus is that

residents can follow up outpatients with chronic conditionsfor alongtime. Timeisagreatteaching tool, much better than aseries of snapshots of different patients in different phases of their disease.

\section{REVALIDATION}

Specialist revalidation takes place every five years. Some Dutch specialist societies, such as those for cardiology and surgery, have developed rather stringent requirements in terms of procedures performed and courses attended. For neurology the optimum is probably a little less liberal than thecurrent situation (mereparticipation in a course every six months and in a written test every year will suffice).

\section{HEALTH CARE}

Private practice has been completely phased out from academic teaching hospitals over the last 20 years. George Bernard Shaw would be shocked to hear that in manygeneral hospitalsin the N etherlands medical specialists still behave as entrepreneurs, but this is not much different from the situation in many other countries in Europe. The result is the usual pecking order of income, with cardiothoracic surgeons at the top and paediatricians at the bottom. Neurologists in general hospitals can still somewhat bolster their income with electrophysiological procedures and by economizing on time. Some young neurologists are still lured away from universities by these prospects. At any rate, even this system is now under pressure and 'socialized medicine' (as Americans call it with some disdain) is slowly spreading from Scandinavia downwards.

\section{RESEARCH}

Government cuts in the 1980s made academic hospitals acutely aware that research is not an activity for the chosen few, but part of the job. This has often resulted in focusing of research activities to subspecialty areas and in theformation of research groupswith a coreof at least four or five consultant physicians. Such groups provide the 'critical mass' that attracts new grants as well as new talents. In this way - to name a few main topics - research on dementia tends to be centred in Amsterdam (Free University and Academic M edical Centre); on neuromuscular diseasein Amsterdam (AM C), Rotterdam, Utrecht and Nijmegen; on cerebrovascular disease in Rotterdam, Utrecht, Maastricht and Amsterdam (AMC); and on neurogenetics in Leiden and Nijmegen. Of course there are differences in emphasis even within these areas. Although the research output is comparatively good for Dutch medicineasa whole, there is no reason for complacency. The key to success is teamwork, with asfew starsas possible- a lesson theGreekstaught therest of Europeat therecent football championship in Portugal.

\section{ACKNOWLEDGEMENTS}

I received helpful comments from John Wokke, Jaap Kappelleand Gabriel Rinkel. 